\title{
Letter to the Editor: Commentary on "Is it possible to predict the origin of epithelial cells? - A comparison of secondary transfer of skin epithelial cells versus vaginal mucous membrane cells by direct contact, M.M. Bouzga et al., Science \& Justice, https://doi.org/10.1016/j.scijus.2020.02.003"
}

\author{
Alex Biedermann ${ }^{\mathrm{a}, *}$ \\ ${ }^{a}$ University of Lausanne, School of Criminal Justice, 1015 Lausanne-Dorigny, Switzerland
}

\begin{abstract}
This letter to the Editor comments on the paper "Is it possible to predict the origin of epithelial cells? - A comparison of secondary transfer of skin epithelial cells versus vaginal mucous membrane cells by direct contact" by M.M. Bouzga et al. (Science \& Justice, https://doi.org/10.1016/j.scijus.20al.20.02.003).
\end{abstract}

\section{Dear Editor,}

In their recent article, Bouzga et al. [4] ask the question "Is it possible to predict the origin of epithelial cells?" (emphasis added). This is a non-question because in the context of inference about DNA transfer mechanisms considered by the authors, there is nothing to predict. This letter explains why there is nothing to predict here and why the authors' contentions to the contrary - found similarly in papers by other authors throughout mainstream forensic science literature ${ }^{1}-$ are confusing. They contribute to forensic science as being perceived as a discipline that not only overstates its conclusions, but creates expectations that science currently cannot fullfill.

Bouzga et al. studied the quantity of human DNA and the proportion of female DNA collected on men in controlled situations. They focused on two distinct types of activities: vaginal penetration versus non-intimate social interaction. The main finding of the paper is that both the total amount of human DNA and the proportion of female DNA are greater in the former situation than in the latter. This observed difference, the authors conclude, makes it "therefore possible to predict the scenario that lead [sic $]^{2}$ to deposition" (emphasis added) of the detected DNA.

The main point here is that we do not predict the past. To illustrate why this is a linguistic and argumentative contortion, consider the 'wet grass' example, an archetype illustration for probabilistic reasoning presented widely in the AI literature since the 1980s [e.g. 17, at p. 56]. Suppose you walk out of your house in the morning and you observe that the grass is wet. You wonder what happened (note the italics here to emphasise past tense) during the

\footnotetext{
${ }^{*}$ Corresponding author

Email address: alex.biedermann@unil.ch (Alex Biedermann)

${ }^{1}$ See references in later sections of this letter.

${ }^{2}$ It is unclear what exactly the authors mean here. If they mean past tense, it should be 'led', if they mean present tense, it should be 'leads'. For the remainder of this letter, we suppose that the authors meant past tense.
} 
night. Did it rain? Or was the sprinkler on? If we followed Bouzga et al.'s terminology, we should be expressing ourselves along the following lines: "Is it possible to predict whether rain or the sprinkler caused the grass in front of my house to be wet this morning?" But this makes no sense, because the event already occurred! ${ }^{3}$ We do not commonly use the term prediction for events that happened in the past. ${ }^{4}$ It suffices to consider the latin origins of the word, consisting of pre- (meaning 'before') and dicere (meaning 'to say'). This is also the way in which standard Bayesian statistical theory uses the term. Most naturally, in our wet grass example, we can consider the probability of a future event (i.e., wet grass tomorrow), given what we know today. Technically speaking, probability assertions about future events are made using so-called predictive distributions, though a probabilistic statement itself about a future event is not a prediction - because this suggests a definite assertion about something that is actually affected by uncertainty. ${ }^{5}$ Instead, what is meant here is a prevision. ${ }^{6}$ In turn, contemplating the causes (e.g., rain) of observed effects (e.g., wet grass) has to do with (probabilistic) inference, fundamentally [18].

In defense of Bouzga et al. it should be mentioned, however, that they are not the only authors who use the term prediction in a confusing way. Forensic science literature is replete with this use of the term, most notably in forensic genetics. A typical example is the 'prediction' of externally visible characteristics, such as hair and eye color [e.g. 5]. The term 'prediction' also pollutes language in the vast literature on AI in the law. The European ethical Charter on the use of Artificial Intelligence in judicial systems and their environment conjectures that one reason for "this abuse of language and the spread thereof" $[9$, at p. 30] is the careless carrying-over of this term from core science disciplines to applied contexts.

The authors may reply that this amounts to splitting hairs over semantics, and that it is clear that what they meant to do was trying to determine the (probable) cause of detected DNA, that is whether it is the result of primary transfer rather than secondary transfer. But still, this would be ill-conceived in at least two ways.

First, the particular statistical methods used by the authors suggest the widespread but false idea that the answer to the question 'what is the cause of this observation' could somehow be cranked out from scientific data alone. This is not to deny that data can be useful and indeed the authors' data are very useful in this context. But in legal applications, providing a substantial answer to how a particular observation came to be requires more than scientific data only. Again, standard Bayesian methodology clarifies this in terms of the prior (probability) [e.g., 15]. The authors may invoke that this was not their concern and that their only purpose was to fit a function to their data and carry out a performance analysis under strictly controlled experimental conditions. While this is a respectable goal, we need to distinguish between, on the one hand, the value of generating hard data in the first place (in this respect, Bouzga et al. provide valuable research) and, on the other hand, the further uses of any data thus generated. In relation to the latter point, it remains crucial not to lose sight of what the reported data treatments might suggest to other researchers in the field and to practitioners who encounter DNA in particular case circumstances. Specifically, we should avoid sterile perspectives that Feyerabend described as follows: "And there are further scientists who do just curve fitting. They have a few results and they try to find the best curve between them. If you ask them if they think they are dealing with

\footnotetext{
${ }^{3}$ See a comment by Spiegelhalter [21, at p.149] to the same effect regarding a popular algorithm contest aiming at 'predicting' which passengers survived the sinking of the Titanic.

${ }^{4}$ Some philosophers of science accept a broader definition, including "inference from the observed to the unobserved, regardless of temporal relation." [20, at p. 684]

${ }^{5}$ There is, however, a way in which one can be categorical in this context, i.e. in the sense of a decision to behave as if a particular event is true. But this requires decision theory $[22,6]$ which is beyond the scope of the discussion here.

${ }^{6}$ For a comprehensive account of the distinction between prediction and prevision, see Bruno de Finetti's Theory of Probability [8]. For a commentary on the importance of this distinction in the context of forensic science, see [3].
} 
reality, some will say 'leave me alone, I have nothing to do with that! I've got some nice numbers here and I'm trying to connect them'. Other scientists may answer that they don't quite know." [13, at p. 57]

Second, opining directly as to causes - here alleged modes of transfer - is not the duty of scientists operating in evaluative mode. ${ }^{7}$ Suggesting otherwise amounts to overthrowing, for no reason, fundamental principles of forensic evaluation that have been developed and defended over decades with intense efforts ${ }^{8}$ by researchers [12], practitioners [7], professional associations [2], expert groups [26] and scientific committees [1]. More so, the DNA Commission of the International Society for Forensic Genetics [14] has now clarified not only that forensic scientists must "give their opinion on the results and not on the propositions" [14, at p. 2, emphasis as in original], ${ }^{9}$ but also that propositions used in value of evidence assessments should not even include the word 'transfer'. Instead, scientists should focus on the probability of the DNA findings given propositions regarding alleged activities.

In sum, it can thus be seen that the forensic scientist's work in the legal process and, to a large extent, the legal process itself, is not concerned with prediction. ${ }^{10}$ As regards Bouzga et al.'s paper, the pretense of prediction was unnecessary because in the sentence following immediately after the assertion "it is possible to predict the scenario", the authors caution that "however, there are some limitations", among which they mention nothing less than the embarrassing possibility that "secondary transfer from a good shedder could be mistaken as direct transfer of mucous cells". But again, this is a false problem because the question that is asked in the first place is fundamentally ill-conceived: the focus should be on the findings, not on the proposition. And, above all, asserting simultaneously that "it is possible to predict" and that one could "be mistaken" is blatantly discourteous toward criminal defendants. Readers who disagree with this should ask themselves if they would take any comfort in a case in which their own fate, as a defendant, hinged upon a report by a scientist who engages in such contradictory assertions.

The authors may reject these critiques as a difference of opinion over scientific details that, at the end of the day, are of no impact in practical proceedings. I cannot agree with this: it makes a fundamental difference whether one focuses on the findings given propositions, or the reverse. This is so irrespective of whether one is operating in a pure research context as Bouzga et al. do or whether one is confronting evaluative questions in an actual case. It is not without reason that this difference has been called "the single most important lesson for the logic of evaluative forensic science" [11, at p. 159]. It is important that this lesson reaches all corners of forensic science. As long as the scientific community is not entirely clear about this difference and the precise meaning of specific terminology in this area, there is little hope that forensic science will mature to a state in which it is able to communicate in a scientifically sound way with the judiciary and the public at large. Meanwhile, it is no surprise that legal scholars and practitioners complain that forensic science conclusions are often difficult to understand. This echoes Toulmin's emphasis on scientific writing as an exercise in the rhetoric of science, "seeing that Rhetoric is not just a corruption of Rationality, but a serious discipline" [24, at p. 201].

Peer reviewed journals such as Science \& Justice should be a forum where high-quality forensic science research is disseminated. These journals should be allies in the ongoing process of scrutinising the field's progress. But how to foster such a development? A rather simple and effective measure would be to apply a more stringent editorial process to papers that, in one way or another, make confusing assertions involving the transposed conditional, for

\footnotetext{
${ }^{7}$ On the difference between evaluative and investigative modes of operation, see Jackson [16].

${ }^{8}$ Many of these works have, by the way, been published in Science \& Justice.

${ }^{9}$ In slightly more technical jargon, this precept is now widely known as that of avoiding to transpose the conditional.

${ }^{10} \mathrm{An}$ important exception to this are assessments at the sentencing stage of a particular convict's tendency to reoffend.
} 
as such papers are not suitable to advance reasoned discourses about forensic science. ${ }^{11}$ This proposal may sound offensive, though it is not original. It is inspired by the decision of a psychology journal that, a few years ago, attracted widespread attention following its policy change to no longer publish papers containing null hypothesis significance tests ( $p$-values) [25]. Thus, such policy changes are feasible and forensic scientists would be well advised to question themselves on these developments as well [23]. ${ }^{12}$

An editorial policy change should also target other spurious assertions found widely in forensic science literature, most notably in connection with identification, individualization and uniqueness claims. As an example, consider the following instance of outdated scientific attitude ${ }^{13}$ of the kind 'trust me, I'm the expert, because I do that all day long': “This uniqueness is obvious to anyone who spends all day looking at medical X-rays.” [19, at p. e13]

In a world - which could be tomorrow - where journals no longer contain such nonsensical sentences, nor transposed conditionals, letters such as the present one, would no longer be necessary.

\section{Acknowledgments}

Alex Biedermann gratefully acknowledges the support of the Swiss National Science Foundation through grant No. BSSGI0_155809.

\section{Conflict of Interest Statement}

The author declares that this letter was written in the absence of any commercial or financial relationships that could be construed as a potential conflict of interest.

\section{References}

[1] C G G Aitken, P Roberts, and G Jackson. Fundamentals of Probability and Statistical Evidence in Criminal Proceedings (Practitioner Guide No. 1), Guidance for Judges, Lawyers, Forensic Scientists and Expert Witnesses, Royal Statistical Society's Working Group on Statistics and the Law, 2010. URL www.rss.org.uk/Images/PDF/influencing-change/ rss-fundamentals-probability-statistical-evidence.pdf.

[2] Association of Forensic Science Providers. Standards for the formulation of evaluative forensic science expert opinion. Science \& Justice, 49:161-164, 2009.

[3] A Biedermann, S Bozza, and F Taroni. Prediction in forensic science: a critical examination of common understandings. Frontiers in Psychology, 6:1-4, 2015.

[4] M.M. Bouzga, G Dørum, K Gundersen, P Kohler, P Hoff-Olsen, and A E Fonneløp. Is it possible to predict the origin of epithelial cells? - a comparison of secondary transfer or skin epithelial cells versus vaginal mucous membrane cells by direct contact. Science \& Justice, in press, 2020.

\footnotetext{
${ }^{11}$ The feasibility of this proposal hinges upon the capacities of reviewers to detect transposed conditionals. Authors of papers containing transposed conditionals flagged up by reviewers may be given the opportunity to revise their work to avoid a ban.

${ }^{12} \mathrm{As}$ an aside, note that Bouzga et al. also work with $p$-values.

${ }^{13}$ As already noted by Evett some 30 years ago, "for an expert to say 'I think this is true because I have been doing this job for $x$ years' is, in my view, unscientific" [10, at p. 21].
} 
[5] K Breslin, B Wills, A Ralf, M Ventayol Garcia, M Kukla-Bartoszek, E Pospiech, Freire-Aradas. A, C Xavier, S Ingold, M de La Puente, KJ van der Gaag, N Herrick, C Haas, W Parson, C Phillips, T Sijen, W Branicki, S Walsh, and M Kayser. HIrisPlex-S system for eye, hair, and skin color prediction from DNA: Massively parallel sequencing solutions for two common forensically used platforms. Forensic Science International: Genetics, 43:1-13, 2019.

[6] S A Cole and A Biedermann. How can a forensic result be a "decision"? A critical analysis of ongoing reforms of forensic reporting formats for federal examiners. Houston Law Review, 57:551-592, 2020.

[7] R Cook, I W Evett, G Jackson, P J Jones, and J A Lambert. A model for case assessment and interpretation. Science \& Justice, 38:151-156, 1998.

[8] B de Finetti. Theory of Probability, A Critical Introductory Treatment, Volume 1. John Wiley \& Sons, London, 1974.

[9] European Commission for the Efficiency of Justice (CEPEJ). European ethical Charter on the use of Artificial Intelligence in judicial systems and their environment. Strasbourg, 2018. URL https://rm.coe.int/ ethical-charter-en-for-publication-4-december-2018/16808f699c.

[10] I W Evett. Interpretation: A personal odyssey. In C G G Aitken and D A Stoney, editors, The Use of Statistics in Forensic Science, pages 9-22. Ellis Horwood, New York, 1991.

[11] I W Evett. Evaluation and professionalism. Science \& Justice, 49:159-160, 2009.

[12] I W Evett and B S Weir. Interpreting DNA Evidence. Sinauer Associates Inc., Sunderland, 1998.

[13] P Feyerabend. The Tyranny of Science. Polity Press, Cambridge, 2011.

[14] P Gill, T Hicks, J M Butler, E Connolly, L Gusmão, B Kokshoorn, N Morling, RHA van Oorschot, W Parson, M Prinz, P M Schneider, T Sijen, and D Taylor. DNA Commission of the International Society for Forensic Genetics: Assessing the value of forensic biological evidence - Guidelines highlighting the importance of propositions. Part II: Evaluation of biological traces considering activity level propositions. Forensic Science International: Genetics, 44:1-13, 2020.

[15] C Howson and P Urbach. Scientific Reasoning: The Bayesian Approach. Open Court, 3rd edition, 2005.

[16] G Jackson. The scientist and the scales of justice. Science \& Justice, 40:81-85, 2000.

[17] J Pearl. Probabilistic Reasoning in Intelligent Systems: Networks of Plausible Inference. Morgan Kaufmann Publishers, Inc., San Mateo, 1988.

[18] J Pearl. Causality: Models, Reasoning, and Inference. Cambridge University Press, Cambridge, 2000.

[19] G Quatrehomme, E Biglia, B Padovani, P du Jardin, and V Alunni. Positive identification by X-rays bone trabeculae comparison. Forensic Science International, 245:e11-e14, 2014.

[20] W C Salmon. Why ask “why?”? An inquiry concerning scientific explanation. Proceedings and Addresses of the American Philosophical Association, 51:683-705, 1978.

[21] D J Spiegelhalter. The Art of Statistics, Learning from Data. Pelican Books, London, 2019.

[22] F Taroni, S Bozza, A Biedermann, G Garbolino, and C G G Aitken. Data Analysis in Forensic Science: a Bayesian Decision Perspective. Statistics in Practice. John Wiley \& Sons, Chichester, 2010.

[23] F Taroni, A Biedermann, and S Bozza. Statistical hypothesis testing and common misinterpretations: Should we abandon $p$-value in forensic science applications? Forensic Science International, 259:e32-e36, 2016.

[24] S Toulmin. Return to Reason. Harvard University Press, Cambridge, Massachusetts, 2001.

[25] D Trafimow and M Marks. Editorial. Basic and Applied Social Psychology, 37:1-2, 2015.

[26] SM Willis, L McKenna, S McDermott, G O’Donell, A Barrett, B Rasmusson, A Nordgaard, CEH Berger, MJ Sjerps, JJ Lucena-Molina, G Zadora, CCG Aitken, T Lovelock, L Lunt, C Champod, A Biedermann, TN Hicks, and F Taroni. ENFSI guideline for evaluative reporting in forensic science, Strengthening the evaluation of forensic results across Europe (STEOFRAE). Dublin, 2015. 